\title{
AVALIAÇÃO DA GERMINAÇÃO DE SEMENTES DE PEQUIZEIRO (Caryocar brasiliense Camb.) SUBMETIDAS EM DIFERENTES CONCENTRAÇÕES DE ÁCIDO GIBERÉLICO
}

\author{
Edvan Costa da Silva ${ }^{1}$, Léo Vieira Leonel ${ }^{2}$ \\ ${ }^{1}$ Mestrando em Produção Vegetal, Universidade Estadual do Goiás / UEG, Ipameri - GO. \\ ${ }^{2}$ Mestrando em Agroecologia, Universidade Estadual do Maranhão / UEMA, São Luís - MA.
}

RESUMO: O pequi apresenta reduzida taxa e velocidade de emergência. Os períodos de emergência variam de um a oito meses, utilizando-se tratamentos para a quebra da dormência. O objetivo deste trabalho foi verificar a influência de diferentes concentrações de ácido giberélico na germinação das sementes de pequizeiro em condições de viveiro. O experimento foi realizado no viveiro de mudas da Usina Hidrelétrica de Estreito - MA, com o delineamento inteiramente casualizado com quatro tratamentos e cinco repetições, onde se obteve uma semente por parcela e que cada repetição teve 4 parcelas. E todas as sementes foram escarificadas. Os tratamentos foram: T0 - 24 horas em água (Testemunha); T1 - $1000 \mathrm{ppm}$ $\left(\mathrm{GA}_{3}\right) ; \mathrm{T} 2-1375 \mathrm{ppm}$ de $\left(\mathrm{GA}_{3}\right)$ e T3 $-1500 \mathrm{ppm}$ de $\left(\mathrm{GA}_{3}\right)$. Com 35 dias corrido, o tratamento 1 (T1) foi que se obteve maiores valores de germinação, maior altura das mudas e a maior quantidade de folhas quando se comparados aos outros tratamentos.

Palavras-chave: Cerrado. Dormência. Giberelinas.

\section{EVALUATION OF SEED GERMINATION OF PEQUIZEIRO (Caryocar brasiliense Camb.) SUBMITTED IN DIFFERENT CONCENTRATIONS OF GIBERÉLICO ACID}

\begin{abstract}
Pequi has reduced rate and emergence rate. Emergency periods ranging from one to eight months, using treatments for breaking dormancy. The aim of this study was to investigate the influence of different concentrations of gibberellic acid on germination pequizeiro seeds in nursery conditions. The experiment was carried out in the seedling nursery of the Estreito - MA Hydroelectric Plant, with a completely randomized design with four treatments and five replications, where one seed was obtained per plot and each replication had four plots. And all the seeds were scarified. The treatments were: T0 - 24 hours in water (control); T1 - 1000 ppm (GA3); T2 - 1375 ppm (GA3) and T3 - 1500 ppm (GA3). 35-day run, treatment 1 (T1) was obtained which was higher germination values, increased plant height and the greatest amount of sheets when compared to other treatments.
\end{abstract}

Key words: Gibberellins. Numbness. Thick.

Cultura Agronômica, Ilha Solteira, v.26, n.2, p.217-223, 2017 


\section{INTRODUÇÃO}

O pequizeiro (Caryocar brasiliense Camb.) é uma espécie arbórea nativa do Cerrado brasileiro, pertencente à família Caryocaraceae. De acordo com a região de ocorrência, ele recebe outras denominações, como: pequi, piqui, piquiá-bravo, amêndoa-de-espinho, grãode-cavalo, pequiá, pequiá-pedra, pequerim, suari e piquiá. É uma planta semidecídua, heliófita, seletiva xerófita, características típicas do Cerrado brasileiro. Ocorre geralmente em agrupamentos mais ou menos densos, tanto em formações primárias como secundárias (LORENZI, 2000; DEUS, 2008).

Sua ocorrência abrange todo o Cerrado brasileiro, sendo encontrado principalmente em regiões de cerradão, cerrado denso, cerrado e cerrado ralo, com distribuição nos Estados da Bahia, Ceará, Distrito Federal, Goiás, Maranhão, Mato Grosso, Mato Grosso do Sul, Minas Gerais, Pará, Piauí, Rio de Janeiro, São Paulo e Tocantins (RIBEIRO, 2000). Algumas espécies também são encontradas nas savanas da Costa Rica ao Paraguai (MACEDO, 2005).

Parece ser consenso comum entre os pesquisadores que a propagação do pequizeiro por sementes é complicada. As sementes apresentam forte dormência (ARAÚJO, 1995), e as baixas taxas e velocidades de germinação dificultam o trabalho em viveiros, aumentam o custo de produção das mudas e, principalmente, dificultam o planejamento dos plantios definitivos.

A aplicação exógena de reguladores de crescimento modifica, em algumas sementes, as exigências de temperatura e induz a germinação. Neste sentido, o ácido abscísico, giberélico, citocininas e etileno, estão intimamente relacionados com inibição e promoção da germinação (REYNOLDS; THOMPSON, 1973).

Diante disso, o presente trabalho teve como objetivo verificar a influência de diferentes concentrações de ácido giberélico $\left(\mathrm{GA}_{3}\right)$ na germinação das sementes de pequizeiro em condições de viveiro localizado.

\section{MATERIAL E MÉTODOS}

O estudo experimental foi realizado nas dependências do Viveiro da Usina Hidrelétrica de Estreito - MA. Os frutos de pequi foram coletados na cidade de Darcinópolis - TO, somente os frutos que estavam caídos no chão. Foi feita uma seleção visual destes frutos, tentando evitar frutos doentes ou danificados.

As sementes usadas nos testes de germinação foram semeadas em sacos plásticos, contendo substrato arenoso de textura mediana. $\mathrm{O}$ experimento foi realizado em delineamento inteiramente casualizado com quatro tratamentos e cinco repetições. Para cada parcela amostral foi usado apenas uma semente, ressaltando que cada repetição foi constituído por 4 parcelas (sacos). Antes de mergulhar as sementes na solução, elas foram escarificadas. Os tratamentos foram: T0 - 24 horas em água (Testemunha); T1 - 1000 ppm de ácido giberélico; T2 - 1375 ppm de ácido giberélico e T3 - 1500 ppm de ácido giberélico. 
As avaliações da germinação foram realizadas aos 60, 75, 90, 105, 120 e 135 dias após o semeio das sementes nos sacos plásticos, nessas ocasiões foram mensuradas as biometrias e os incrementos foliares das sementes germinadas. Sendo consideradas germinadas as sementes que originaram plântulas normais, com todas as estruturas essenciais, demonstrando, assim, sua aptidão para produzirem plantas normais sob condições favoráveis de campo.

Foi determinado o Índice de Velocidade de Emergência (IVE), registrando-se diariamente o número de plântulas emergidas, com parte aérea formada, até o dia quando houve estabilização da emergência, e este foi calculado pela fórmula proposta por Maguire (1962): IVE = E1/N1 + E2/N2 + ... En/Nn Onde: IVE = índice de velocidade de emergência. $\mathrm{E} 1, \mathrm{E} 2, \ldots \mathrm{En}$ = número de plântulas normais computadas na primeira contagem, na segunda contagem e na última contagem. $\mathrm{N} 1, \mathrm{~N} 2, \ldots \mathrm{Nn}=$ número de dias da semeadura à primeira, segunda e última contagem.

Os resultados foram expressos em porcentagem de germinação, correspondendo à proporção do número de sementes que produziram plântulas classificadas como normais. Assim, todos os dados de cada tratamento passaram por cálculos a fim de serem determinadas as médias de cada repetição, no sentido de avaliar qual tratamento contribuiu melhor para o desenvolvimento das mudas, levando em consideração os parâmetros de quantidade, número de folhas e altura. As análises de variância dos experimentos foram feitas através do teste $\mathrm{F}$ e os resultados obtidos comparados através do teste de Tukey a 5\% de probabilidade. Os resultados foram processados pelo software ASSISTAT 7.6 beta.

\section{RESULTADOS E DISCUSSÃO}

As primeiras sementes começaram a germinar 35 dias após a seu semeio, isso para o T1 (1000 ppm de ácido giberélico). As percentagens médias de germinação variaram de 15,0\% a 35,0\%, nas sementes tratadas com o ácido giberélico. Para T0 não foi constatado germinação (Tabela 1).

Tabela 1. Porcentagem de Germinação de pequi (Caryocar brasiliense), aos 135 dias após o plantio.

\begin{tabular}{ccc}
\hline Tratamentos & $\begin{array}{c}\text { Germinação } \\
(\boldsymbol{\%})\end{array}$ & $\begin{array}{c}\text { Índice de Velocidade de } \\
\text { Emergência (IVE) }\end{array}$ \\
\hline T0 (Testemunha) & 0,0 & 0,0 \\
T1 (1000 ppm de $\left.\mathrm{GA}_{3}\right)$ & 35,0 & 0,31 \\
T2 (1350 ppm de $\left.\mathrm{GA}_{3}\right)$ & 20,0 & 0,15 \\
T3 (1500 ppm de $\left.\mathrm{GA}_{3}\right)$ & 15,0 & 0,09 \\
\hline
\end{tabular}

$\mathrm{T} 0=$ Tratamento $0, \mathrm{~T} 1=$ Tratamento $1, \mathrm{~T} 2=$ Tratamento 2 e $\mathrm{T} 3=$ Tratamento 3.

Estes resultados estão de acordo com Melo Júnior et al. (2004), que sugerem que a alta variação nos índices deve-se à frequência de alelos entre e dentro de uma mesma população desta espécie. Segundo estes autores, os altos índices de diversidade sugerem a existência de 
seleção em favor dos heterozigotos e, assim, baixa endogamia nas populações. Daí a importância de se conhecer a planta matriz, para a obtenção de mudas, quando se dispõe de materiais com características agronômicas e comerciais superiores.

Esses resultados assemelham, em parte, dos obtidos por Dombroski et al. (1998), que encontraram maiores valores de percentagem de emergência, quando as sementes receberam tratamento com regulador, para quebra de dormência. Assemelham, também, daqueles observados por Pereira et al. (2002), os quais, comparando as concentrações de $500 \mathrm{mg} \mathrm{L}^{-1} \mathrm{e}$ $1000 \mathrm{mg} \mathrm{L}^{-1}$, constataram superioridade da primeira alternativa, sendo que as sementes tratadas apresentaram até $35 \%$ de emergência, enquanto aquelas que foram imersas em água, pelo mesmo período, apresentaram $2,8 \%$ de emergência.

Os valores aqui obtidos (35\% de emergência), são superiores aos encontrados por Bernardes et al. (2008), que relataram 30,8\%, como ponto de máxima emergência nas sementes tratadas com $345 \mathrm{mg} \mathrm{L}^{-1}$ de $\mathrm{GA}_{3}$, em sementes recém-coletadas. Portanto, o armazenamento das sementes, para semeadura no período chuvoso seguinte, pode resultar em benefício ao viveirista ou produtor que tenha como objetivo produzir mudas, ou efetuar o plantio diretamente no campo.

A Figura 1 representa muito bem a germinação das sementes de pequi (Caryocar brasiliense), aos 135 dias após o semeio nos seus diferentes tratamentos. Notando-se diferença expressiva no tratamento $\mathrm{T} 1$ (1000 ppm de $\left.\mathrm{GA}_{3}\right)$ em relação aos demais tratamentos, onde sua porcentagem obteve um valor de $35 \%$ de germinação.

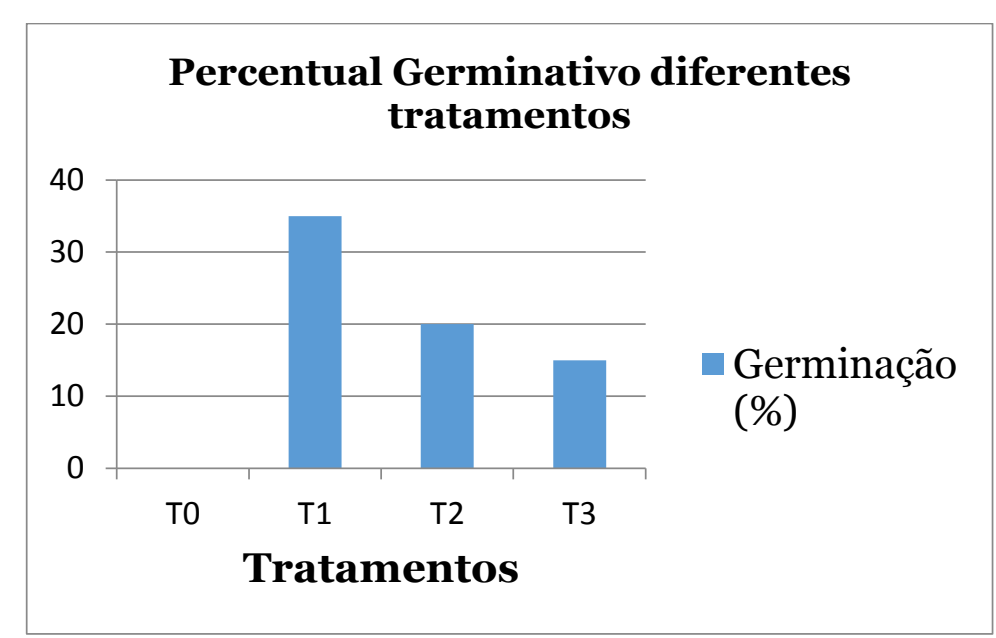

Figura 1. Percentual germinativo dos diferentes tratamentos.

A utilização de $\mathrm{GA}_{3}$ pouco afetou a percentagem de emergência das plantas, visto que apenas as sementes do tratamento 1 (1000 ppm de ácido giberélico), houve significância pelo teste de Tukey a $5 \%$ de probabilidade (Tabela 2 ).

Houve efeito das concentrações de $\mathrm{GA}_{3}$ na quantificação de folhas e altura das mudas de pequi (Caryocar brasiliense). Para o tratamento 0 (testemunha), tanto a quantificação de folhas como a altura das mudas, com valores de 0,0 e 00 respectivamente, o resultado foi não significativo. O tratamento 1 (1000 ppm de $\left.\mathrm{GA}_{3}\right)$, a quantificação de folhas e altura das 
mudas, com valores de 5,7 e 9,3 respectivamente, o resultado foi significativo se comparado com os demais tratamentos. E para os tratamentos 2 (1350 ppm de $\left.\mathrm{GA}_{3}\right)$ e 3 (1500 ppm de $\mathrm{GA}_{3}$ ), tanto a quantificação de folhas como a altura das mudas não houve significância, pois estatisticamente não diferem entre si.

O teste F mostrou-se significativo a 5\% de significância para ambos os parâmetros. Concluímos na prática que as concentrações de $\mathrm{GA}_{3}$ testados mostraram diferenças entre elas, ou seja, alguma concentração pode ser recomendada como a melhor, pois estatisticamente todas diferem entre si.

Tabela 2. Quantificação de Folhas e Altura das Mudas de pequi (Caryocar brasiliense), aos 135 dias após o plantio.

\begin{tabular}{ccc}
\hline Tratamentos & $\begin{array}{c}\text { Quantificação de } \\
\text { Folhas }\end{array}$ & $\begin{array}{c}\text { Altura das } \\
\text { Mudas }\end{array}$ \\
\hline T0 (Testemunha) & $0,00000 \mathrm{~b}$ & $0,00000 \mathrm{~b}$ \\
T1 $\left(1000\right.$ ppm de $\left.\mathrm{GA}_{3}\right)$ & $5,78400 \mathrm{a}$ & $9,38800 \mathrm{a}$ \\
T2 $\left(1350\right.$ ppm de $\left.\mathrm{GA}_{3}\right)$ & $3,81640 \mathrm{ab}$ & $5,44440 \mathrm{ab}$ \\
T3 $\left(1500\right.$ ppm de $\left.\mathrm{GA}_{3}\right)$ & $1,65040 \mathrm{ab}$ & $2,38840 \mathrm{ab}$ \\
\hline
\end{tabular}

Médias com a mesma letra na coluna não diferem pelo teste de Tukey a 5\% de probabilidade.

Como houve significância a 5\% de probabilidade partiu-se para o teste de Tukey e posteriormente para as comparações de médias, com o objetivo real de encontrar qual seria o melhor tratamento (Tabela 2). E foi encontrado o valor de 39,45 \% de coeficiente de variância para o parâmetro quantificação de folhas e para o parâmetro altura das mudas o valor encontrado foi de $38,54 \%$ de coeficiente de variância.

A Figura 2 mostra bem os resultados, onde os valores superiores tanto da quantificação de folhas como da altura das mudas ficou expresso no tratamento (T1), no qual esse tratamento recebeu uma concentração de 1000 ppm de $\mathrm{GA}_{3}$. Além disso, demonstra também que por mais que os tratamentos 2 e 3 , tenham obtido uma média maior que o da testemunha, eles não apresentaram significância ao ponto de ser recomendo como os melhores.

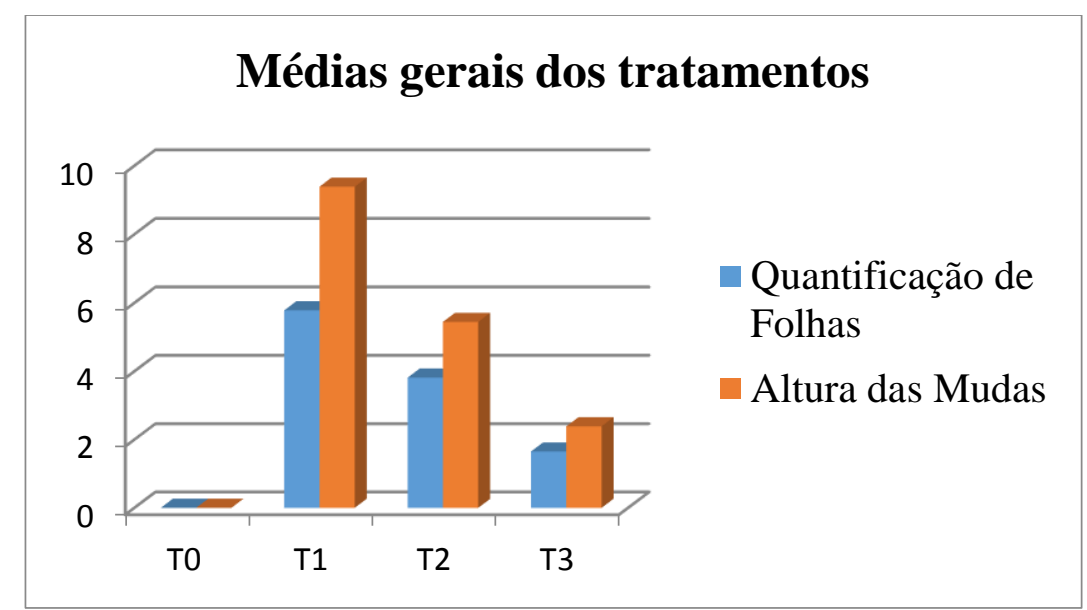

Figura 2. Médias Gerais dos tratamentos nos diferentes parâmetros.

Cultura Agronômica, Ilha Solteira, v.26, n.2, p.217-223, 2017 


\section{CONCLUSÃO}

A aplicação de ácido giberélico reduziu o tempo médio para germinação e reduziu a taxa de sementes germinadas.

A altura e a quantidade de folhas por mudas de pequi (Caryocar brasiliense) correspondem, a diminuição das concentrações de $\mathrm{GA}_{3}$.

A utilização de $\mathrm{GA}_{3}$ na dosagem de 1000 ppm proporcionou maior taxa de germinação das sementes e maior IVE das plântulas de pequi.

Estudos ainda são necessários, visando obter informações sobre a influência exata das concentrações de $\mathrm{GA}_{3}$ na quebra de dormência das sementes de pequi.

\section{REFERÊNCIAS BIBLIOGRÁFICAS}

ARAÚJO, F. D. A review of caryocar brasiliense (Caryocaraceae): an economically valuable of central Brazilian Cerrados. Economic Botany, Bronx, v. 49, n. 1, p.40-48, 1995.

BERNARDES, T. G.; NEVES, R. V.; REZENDE, C. F. A.; BORGES, J. D.; CHAVES, L. J. Propagação sexuada do pequizeiro (Caryocar brasiliense Camb.) estimulada por ácido giberélico. Pesquisa Agropecuária Tropical, Goiânia, v. 38, n. 2, p.71-77, 2008.

DEUS, T. N. Extração e caracterização de óleo do pequi (Caryocar brasiliensis Camb.) para o uso sustentável em formulações cosméticas óleo/água (O/A). 2008. 75 f. Dissertação (Mestrado em Ecologia e Produção Sustentável) - Programa de Pósgraduação Multidisciplinar, Pontifícia Universidade Católica de Goiás, Goiânia, 2008.

DOMBROSKI, J. L. D.; PAIVA, R.; CAMARGO, I. P. Efeito da escarificação sobre a germinação do pequizeiro. Revista Brasileira de Fruticultura, Cruz das Almas, v. 20, n. 1, p.68-73, 1998.

LORENZI, H. Árvores brasileiras: manual de identificação e cultivo de plantas arbóreas nativas do Brasil. v. 1. Nova Odessa: Plantarum, 2000. 384 p.

MACEDO, J. F. Pequi: do plantio à mesa. Belo Horizonte: Empresa de Pesquisa Agropecuária de Minas Gerais, 2005. 44 p. (Boletim Técnico)

MAGUIRE, J. D. Speed germination-aid in selection and evaluation for seedling emergence and vigor. Crop Science, Madison, v. 2, p.176-177, 1962.

MELO JÚNIOR, A. F.; CARVALHO, D.; POVOA, J. S. R.; BEARZOLI, E. Estrutura genética de populações naturais de pequizeiro (Caryocar brasiliense Camb). Scientia Forestalis, Piracicaba, v. 66, p.56-65, 2004.

PEREIRA, A. V.; PEREIRA, E. B. C; JUNQUEIRA, N. T. V. Enxertia de mudas de pequizeiro. Planaltina: Embrapa Cerrados, 2002. 26 p.

Cultura Agronômica, Ilha Solteira, v.26, n.2, p.217-223, 2017 
REYNOLDS, T.; THOMPSON, P. A. Effects of Kinetin, Gibberellins and ( \pm ) Abscisic acid on the Germination of Lettuce (Lactuca sativa). Physiologia. Plantarum, Lund, v. 28, p.516$522,1973$.

RIBEIRO, R. F. Pequi o rei do cerrado. Belo Horizonte: Rede Cerrado, 2000. 62 p. 